\title{
Audio Noise Reduction Using Low Pass Filters
}

\author{
Ali Osman Mohammed Salih ${ }^{1,2}$ \\ ${ }^{1}$ Information Technology Department, Faculty of Computer Science and Information Technology, University of Alneelain, \\ Khartoum, Sudan \\ ${ }^{2}$ Computer Science and Information Systems Department, Faculty of Science and Arts, Bisha University, Bisha, Saudi Arabia \\ Email: aomohammed@ub.edu.sa
}

How to cite this paper: Salih, A.O.M. (2017) Audio Noise Reduction Using Low Pass Filters. Open Access Library Journal, 4: e3709.

https://doi.org/10.4236/oalib.1103709

Received: June 5, 2017

Accepted: November 7, 2017

Published: November 10, 2017

Copyright $\odot 2017$ by author and Open Access Library Inc.

This work is licensed under the Creative Commons Attribution International License (CC BY 4.0).

http://creativecommons.org/licenses/by/4.0/

\section{(c) (i) Open Access}

\begin{abstract}
The study aimed to filter and remove noise from audio, and in this study researcher followed the descriptive analytical method. The study sample consisted of an audio file and has been save Audio of on a formula (WAV), and the study used matlab 7.10.0 to read sound and design low pass filter, then insert the audio signal with the noise signal into the filter and output a signal audio without noise. The researcher has reached findings that differed according to the rank of the filter. The low pass filter has a great effect on removing noise during the registration process together with the times of implementation.
\end{abstract}

\section{Subject Areas}

Applications of Communication Systems, Artificial Intelligence

\section{Keywords}

Low Pass Filters, Noise, Audio Filtering, IIR Filters, FIR Filters

\section{Introduction}

With the development of communication technology, voice communication has become a major communication media for people to transmit information more convenient [1]. Audio noise reduction system is the system that is used to remove the noise from the audio signals. Audio noise reduction systems can be divided into two basic approaches. The first approach is the complementary type which involves compressing the audio signal in some well-defined manner before it is recorded (primarily on tape). On playback [2], the subsequent complementary expansion of the audio signal which restores the original dynamic range, at the same time has the effect of pushing the reproduced tape noise 
(added during recording) farther below the peak signal level - and hopefully below the threshold of hearing. The second approach is the single-ended or non-complementary type which utilizes techniques to reduce the noise level already present in the source material-in essence a playback only noise reduction system.

\subsection{Filter}

Filters are networks that process signals in a frequency-dependent manner. The basic concept of a filter can be explained by examining the frequency dependent nature of the impedance of capacitors and inductors. Consider a voltage divider where the shunt leg is reactive impedance. As the frequency is changed, the value of the reactive impedance changes, and the voltage divider ratio changes as well. This mechanism yields the frequency dependent change in the input/output transfer function that is defined as the frequency response [3]. Filters have many practical applications. A simple, single-pole, low-pass filter (the integrator) is often used to stabilize amplifiers by rolling off the gain at higher frequencies where excessive phase shift may cause oscillations. A simple, single-pole, high-pass filter can be used to block dc offset in high gain amplifiers or single supply circuits [4] (Table 1).

\section{There are two types of filters:}

1) Finite Impulse Response (FIR) filter.

2) Infinite Impulse Response (IIR) filter.

FIR filters have the following advantages over IIR filters:

1) They can have an exact linear phase.

2) They are always stable.

3) The design methods are generally linear.

4) They can be realized efficiently in hardware.

5) The filter start-up transients have finite duration [4].

\subsection{Low Pass Filter}

Low pass filter: For different low-pass filter, there is different weakening of frequency in each signal. When using it in audio applications, sometimes it is called high-cut filter or treble cut filter [5]. The application of low-pass filter in signal processing is equal to the effect of other areas. There are many types of low-pass filter; the most common one is Butterworth filter and Chebyshev filter (Figure $1)$.

Table 1. Type of filter and purpose.

\begin{tabular}{ccc}
\hline S. $\mathbf{N}$ & Filter & Purpose \\
\hline 1 & Low pass filter & Passes low frequency band \\
2 & High pass filter & Passes high frequency band \\
3 & Band pass filter & Passes selected range of frequency band \\
4 & Band stop filter & Stop selected range of frequency band \\
\hline
\end{tabular}




\subsection{Time-Domain Filters}

1) Finite Impulse Response (FIR) filters-A finite impulse response (FIR) filter is one in which the output signal goes to zero in some finite amount of time.

2) Infinite Impulse Response (IIR) filters-An infinite impulse response (IIR) filter may run for an arbitrarily long period of time and never have the output go to zero. The difference between the two types of filters is that an IIR filter is recursive; i.e., an IIR filter will take its previous output and use it as input for the next output, whereas an FIR filter will take as input the current sample in addition to some previous sample. In other words, an IIR filter has internal feedback while an FIR filter does not (Figure 2 and Figure 3).

\section{Problem Definition}

The aim of study is to reduce the noise from the sound signal assuming that we have a useful voice signal related to a particular material and is the signal of the sound of the noise over the entire wave of the sound signal and the $\mathrm{V}$ is distributed with the noise or noise associated with it, the study problem is to reduce noise or The noise associated with the sound signal can be achieved using the low pass filter. This filter can predict the sound added to the main sound and will clear the noise (Figure 4).

Definition of the problem is shown in Figure 4.

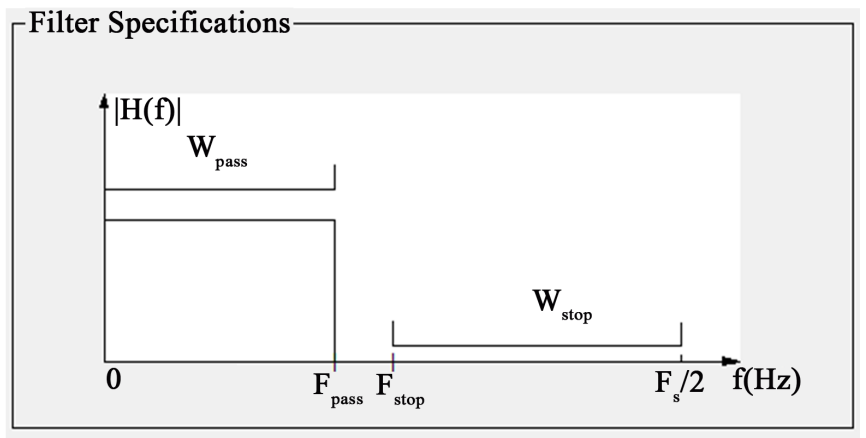

Figure 1. Low pass filter specifications.

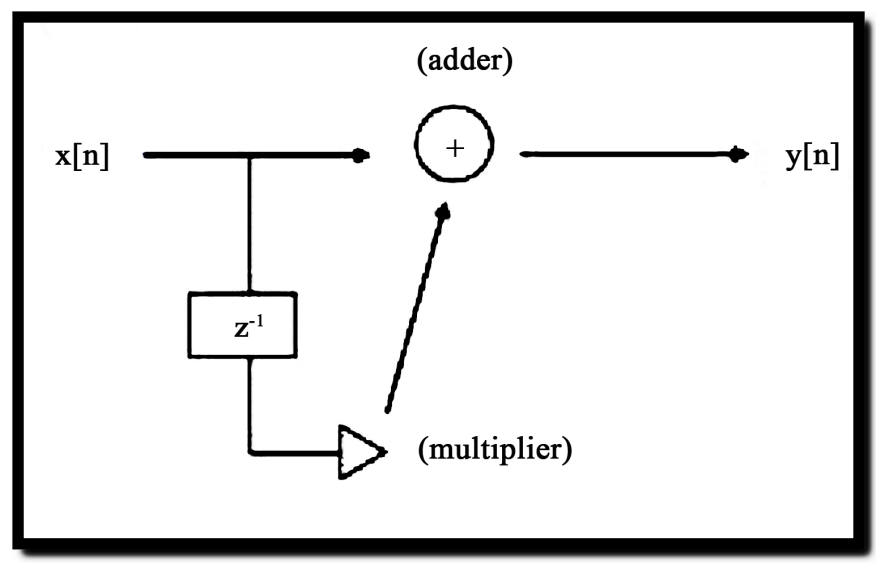

Figure 2. FIR filter. 


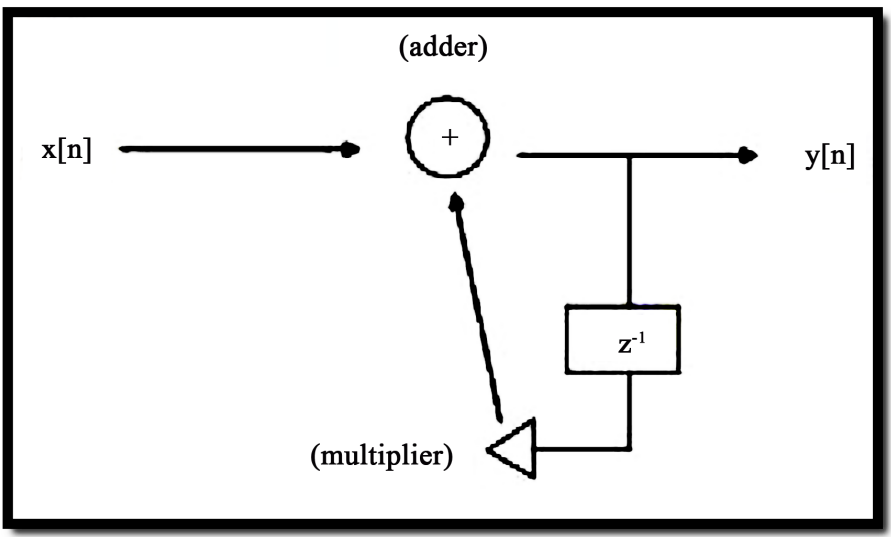

Figure 3. IIR filter.

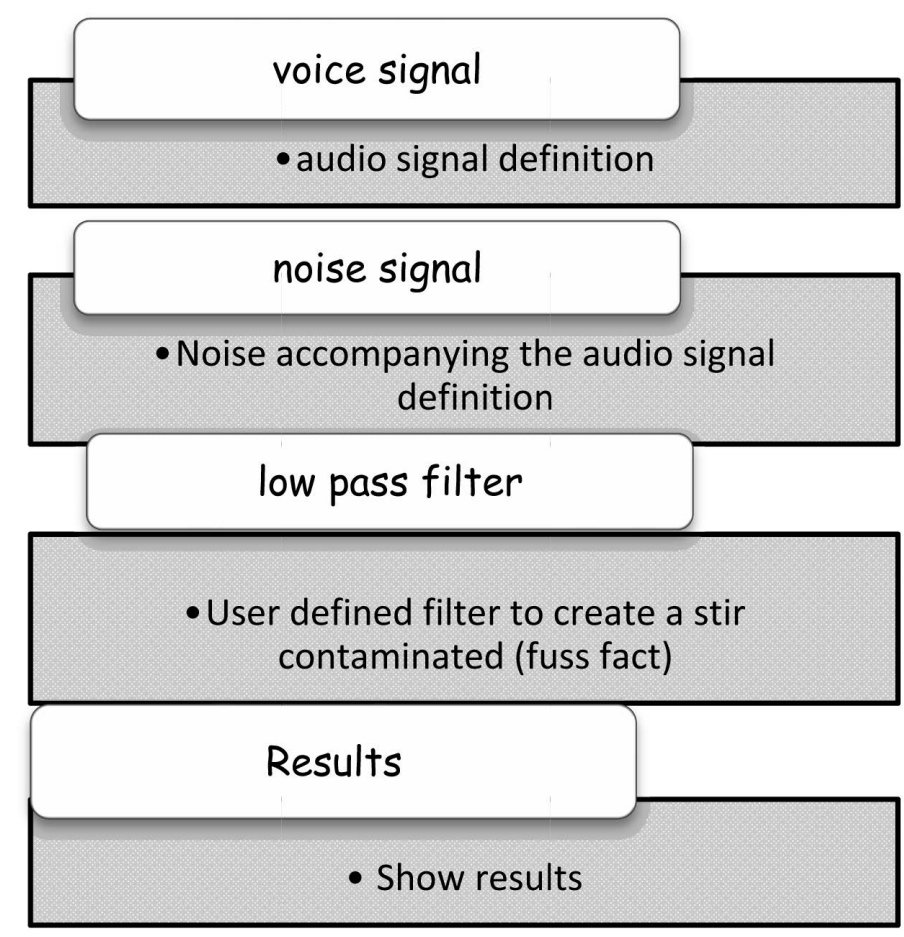

Figure 4. Definition of the problem.

\section{Result}

This shows the implementation results of the dissertation work. There are a different figure that shows how the signals are processed and how the system tools works in MATLAB (Figures 5-11).

1) FIR low pass filter

2) Phase response

3) Magnittude response (dB)

4) For noisy signal sample 1

5) For noiseless signal sample 1

6) For noisy signal sample 2

7) For noiseless signal sample 2 


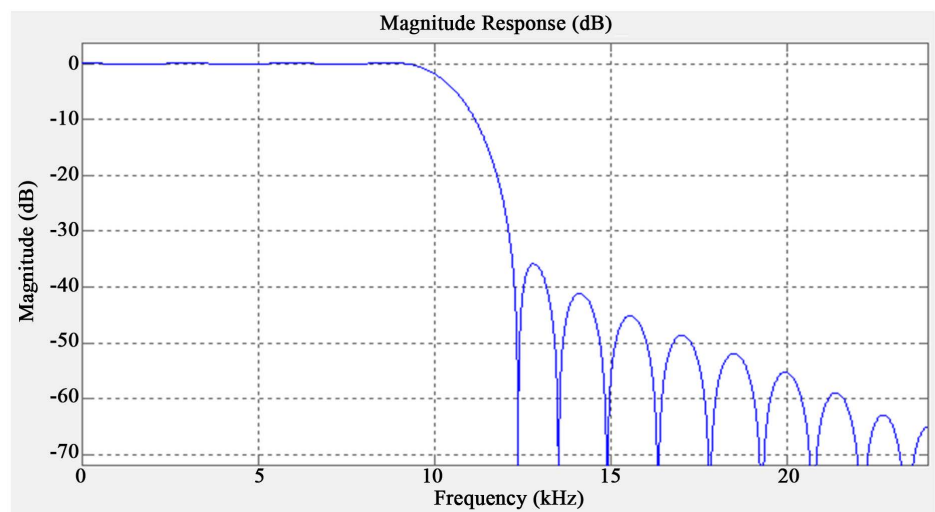

Figure 5. Magnitude response filter.

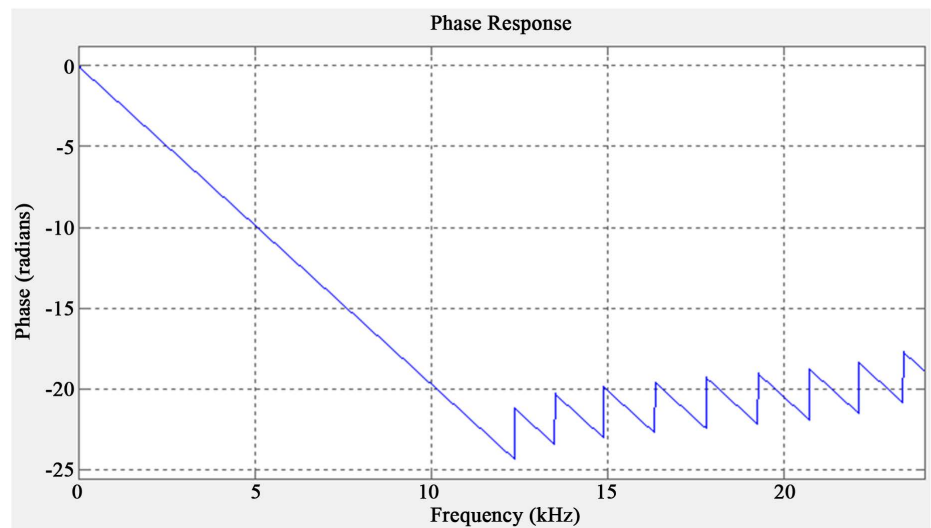

Figure 6. Phase response filter.



Figure 7. Magnitude response (dB) filter.

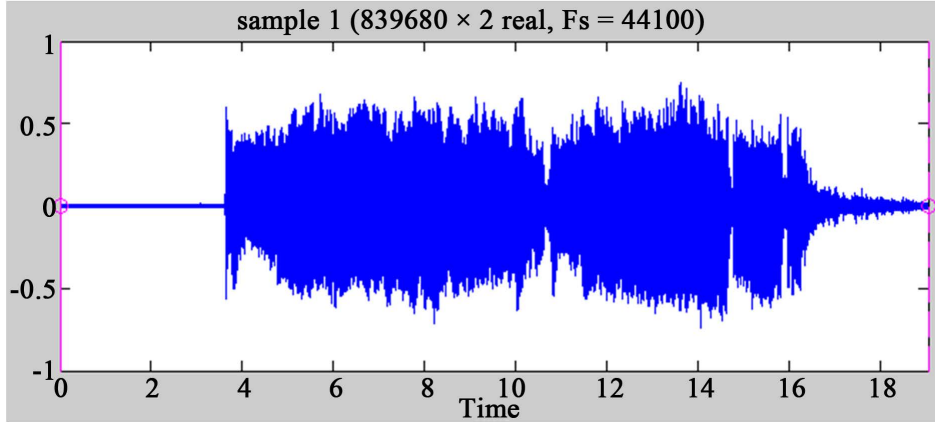

Figure 8 . Noisy signal sample 1. 




Figure 9. Noiseless signal sample 1.

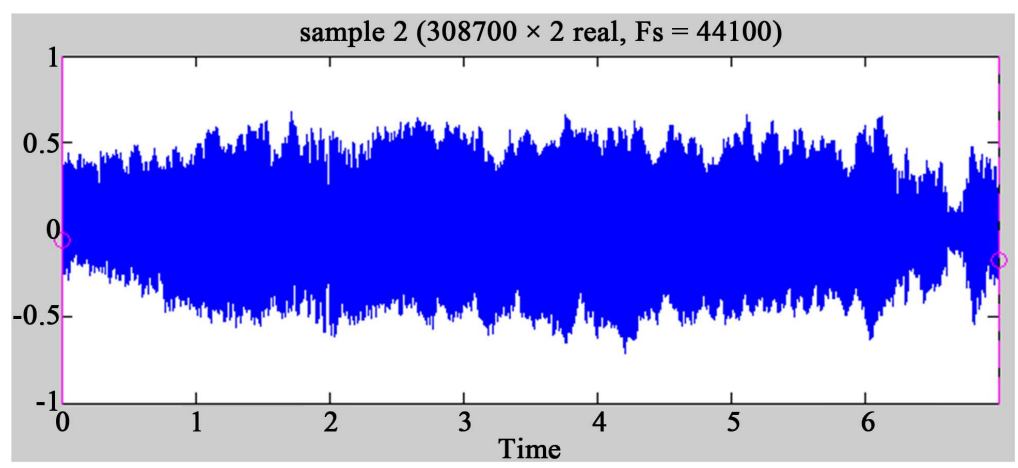

Figure 10. Noisy signal sample 2.

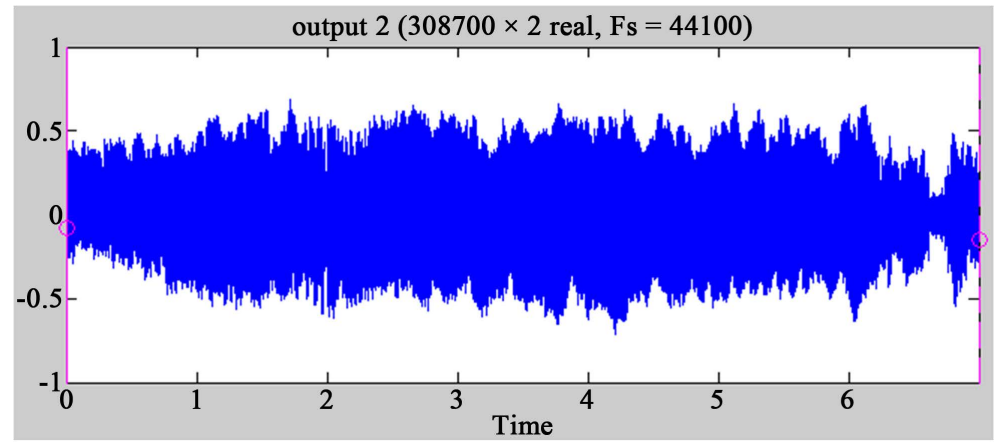

Figure 11. Noiseless signal sample 2.

\section{Conclusion}

In this paper a sound sample was taken in wav format. The sound sample was passed on a low pass filter where a new audio signal was obtained after noise reduction, the low pass filter that is used to reduce the noise from the signals with the different frequency and ripple factor. These filters perform the filtering operations by the computation of difference equations. The coefficient equation and function as the low pass filter are given. Simple design formulas for various equalizers lead to efficient implementations for time-varying filter applications.

\section{References}

[1] Bhagat, R. and Kaur, R. (2013) Improved Audio Filtering Using Extended High Pass Filters. 
[2] Singla, Er.M. and Singh, Mr.H. (2015) Frequency Based Audio Noise Reduction Using Butter Worth, Chebyshev \& Elliptical Filters. International Journal on Recent and Innovation Trends in Computing and Communication.

http://www.ijritcc.org/download/browse/Volume_3_Issues/October_15_Volume_3 Issue_10/1446450414_02-11-2015.pdf

[3] Singh, M. and Garg, Er.N.K. (2014) Audio Noise Reduction Using Butter Worth Filter. http://www.ijcotjournal.org/volume-6/number-1/IJCOT-V6P305.pdf

[4] Gavel, A., LalSahu, H., Sharma, G. and Rahi, P.K. (2015) Design of Lowpass Fir Filter Using Rectangular and Hamming Window Techniques. http://ijiset.com/vol3/v3s8/IJISET_V3_I8_33.pdf

[5] Shenoi, B.A. (2006) Introduction to Digital Signal Processing and Filter Design. 1st Edition, John Wiley \& Sons, Canada.

Submit or recommend next manuscript to OALib Journal and we will provide best service for you:

- Publication frequency: Monthly

- 9 subject areas of science, technology and medicine

- Fair and rigorous peer-review system

- Fast publication process

- Article promotion in various social networking sites (LinkedIn, Facebook, Twitter, etc.)

- Maximum dissemination of your research work

Submit Your Paper Online: Click Here to Submit

Or Contact service@oalib.com 